DOI: 10.12957/demetra.2016.15726

\title{
A sociabilidade exercida em torno do comer: um estudo entre universitários
}

\section{Sociability performed around eating: a study with university students}

Mariana Gaida Viero

Adriane Cervi Blümkel

${ }^{1}$ Centro Universitário Franciscano, Curso de Nutrição. Santa Maria-RS, Brasil.

Correspondência / Correspondence Adriane Cervi Blümke

Centro Universitário Franciscano. Curso de Nutrição.

Rua Silva Jardim, 1175, Conjunto III, Prédio 17. CEP: 97010-491. Santa Maria-RS, Brasil

E-mail:adriblumke@yahoo.com.br

\section{Resumo}

A relação existente entre o homem e a comida ultrapassa os aspectos fisiológicos da alimentação e é marcada pela comensalidade. O objetivo deste estudo é compreender os sentidos e significados do ato alimentar de universitários de uma instituição de ensino superior, a partir de uma reflexão que entende a alimentação como um ato sociocultural e objeto do saber socioantropológico. O estudo caracteriza-se por ser do tipo descritivo, com abordagem qualitativa. A pesquisa foi realizada entre os meses de agosto e dezembro de 2014, com estudantes de uma instituição privada de ensino superior do município de Santa Maria, Rio Grande do Sul. A coleta dos dados foi feita por meio de entrevistas gravadas, as quais foram transcritas e analisadas conforme a técnica de análise de conteúdo. Foram entrevistados dez alunos, de ambos os sexos e de variados cursos. Foi possível notar a influência social e cultural no comportamento alimentar dos estudantes. Também ficou evidente o reflexo da globalização e do tempo nas práticas alimentares dos entrevistados. Sugere-se a realização de novas pesquisas com esse tema, visto ser um campo bastante amplo e que possibilita um outro olhar à alimentação que nem sempre é explorado pela nutrição.

Palavras-chave: Comportamento Alimentar. Alimentação. Socialização. Cultura.

\section{Abstract}

The relationship between mankind and food surpasses the physiological aspects of feeding and is marked by commensality. 
The aim of this study is to understand the senses and meanings of eating by university students at a higher education institution, based on the notion of eating as a sociocultural act and object of socio-anthropological knowledge. The study is descriptive and has a qualitative approach. A survey was conducted between August and December 2014, with students from a private university in the city of Santa Maria, Rio Grande do Sul. Data was collected through recorded interviews which were transcribed and analyzed according to the content analysis technique. Ten students from several programs - both males and females - were interviewed. It could be seen that the students' eating behavior is socially and culturallt influenced. One could also observe an effect of globalization and time on the eating habits of respondents. Further research on this topic is suggested, as it is a very broad field that allows another perspective to feeding which is not always exploited by nutrition.

Key words: Feeding Behavior. Feeding. Socialization. Culture.

\section{Introdução}

A relação existente entre o homem e a comida ultrapassa os aspectos fisiológicos da alimentação e é marcada pela comensalidade. Carneiro" afirma que "a alimentação, além de uma necessidade biológica, é um complexo sistema simbólico de significados sociais, sexuais, políticos, religiosos, éticos, estéticos etc.”. O próprio homem modifica o sentido do consumo alimentar, dando-lhe um significado cultural, ao fazer dos rituais de alimentação uma maneira de se relacionar socialmente. ${ }^{2}$

DaMatta $^{3}$ estabelece uma distinção entre comida e alimento, em que "comida não é apenas uma substância alimentar mas é também um modo, um estilo e um jeito de alimentar-se. E o jeito de comer define não só aquilo que é ingerido, como também aquele que o ingere". Assim, o que é colocado no prato nutre o corpo, mas também sinaliza um pertencimento, servindo como um código de reconhecimento social. ${ }^{3,4}$

Para Bosi \& Prado, ${ }^{5}$ os termos "alimentação" e "nutrição" compreendem aspectos científicos diferenciados. A nutrição constitui-se da racionalização do ato alimentar, priorizando aspectos mensuráveis dos alimentos; e o campo da alimentação refere-se ao ato alimentar como um fenômeno social.

Santos $^{6}$ sugere ainda que "Alimentar-se é um ato nutricional, comer é um ato social, pois constitui atitudes ligadas aos usos, costumes, protocolos, condutas e situações. Nenhum alimento que entra em nossas bocas é neutro. A historicidade da sensibilidade gastronômica explica e é explicada pelas manifestações culturais e sociais como espelho de uma época e que marcaram uma época [...]”. 6 
Carneiro $^{7}$ revela que a história da alimentação tem um objetivo maior que o de estudar um alimento, uma forma de preparo, uma receita ou uma tradição específica. Seu principal desafio é o de abordar o alimento em sua importância maior como um símbolo. Ao encontro disso, Carvalho, Luz \& Prado ${ }^{8}$ acreditam que, historicamente, a comida é um símbolo de riqueza para o homem, e ao longo dos tempos é capaz de revelar a formação das estruturas sociais, desde o instante em que o homem se diferenciou dos outros animais, ao preparar e socializar o alimento. Sendo assim, a história da alimentação engloba muito mais que os alimentos, sua produção, preparo e consumo.

A alimentação, seus hábitos e mudanças envolvem inúmeras relações de fatores. Para Carneiro, ${ }^{1}$ "O que se come é tão importante quanto quando se come, onde se come, como se come e com quem se come”. Em termos fisiológicos, a alimentação só perde em aspecto de importância na sobrevivência humana para a respiração e a ingestão de água. ${ }^{1} \mathrm{O}$ ato de se alimentar ultrapassa a questão fisiológica da busca por nutrientes, indo além, construindo costumes e rituais, gerando relações entre o indivíduo e a sociedade, de modo que a vida social se constitui juntamente com a alimentação. ${ }^{8}$

Ao longo dos tempos ocorreram transformações significativas no comportamento alimentar influenciadas por diversos fatores, entre eles, a falta de tempo do dia a dia, impondo cada vez mais uma alimentação prática e rápida. Giddens ${ }^{9}$ afirma que o modo de vida produzido pela modernidade nos liberta de qualquer tipo tradicional de ordem social e uma de suas caracteristicas é o evidente ritmo de mudança, apesar de o caráter ritualístico ainda existir. Quanto a essas transformações, Garcia ${ }^{10}$ cita a urbanização como um dos fatores. Ela afirma que, em função do tempo, os rituais de alimentação vêm sofrendo alterações, sendo deslocados para locais que sejam condizentes com outras atividades, como no trabalho ou em momentos de entretenimento.

Com base no exposto, o presente trabalho tem como objetivo compreender os sentidos e significados do ato alimentar de universitários de uma instituição de ensino superior, a partir de uma reflexão que entende a alimentação como um ato sociocultural e objeto do saber socioantropológico.

\section{Metodologia}

O presente estudo caracteriza-se por ser do tipo descritivo, com abordagem qualitativa. De acordo com Lefèvre \& Lefèvre, ${ }^{11}$ a pesquisa qualitativa nos dá a oportunidade de compreender profundamente os campos sociais e seus sentidos, referindo-se a vários significados interligados presentes nos depoimentos. A pesquisa foi realizada entre os meses de agosto e dezembro de 2014, com estudantes de uma instituição privada de ensino superior do município de Santa Maria, Rio Grande do Sul. 
Foram entrevistadas pessoas com 18 anos de idade ou mais, de ambos os sexos, matriculados na instituição, que aceitaram participar do estudo mediante esclarecimento prévio e assinatura do Termo de Consentimento Livre e Esclarecido. Essa população foi escolhida pelo fato de apresentar características variadas (idade, sexo, ocupação, renda, filhos etc.), o que se considerou importante nesta pesquisa, pois proporcionou uma visão mais ampla sobre o assunto.

Os participantes foram escolhidos aleatoriamente e de acordo com a disponibilidade em participar nos dias em que a pesquisadora fez a coleta de dados, que foram em dias variados da semana e nos turnos da manhã, tarde e noite. Na pesquisa qualitativa não há necessidade de cálculo amostral, conforme Mayan. ${ }^{12}$ A coleta cessará quando todas as categorias estiverem saturadas por dados, o que acontece quando nenhum dado significativo surge, todos os caminhos foram seguidos e a teoria se confirma..

A coleta dos dados foi feita por meio de entrevistas gravadas, utilizando um roteiro semiestruturado com questões norteadoras, elaboradas pela pesquisadora para este estudo.

Ao término de cada entrevista o material era transcrito na íntegra e posteriormente procediase ao exame dos dados a partir da técnica de análise de conteúdo proposta por Bardin, ${ }^{13}$ que se divide em três fases: pré-análise; exploração do material e tratamento dos resultados, inferência e interpretação. Na pré-análise o pesquisador faz uma leitura flutuante, e em seguida realiza a operação de recorte do texto em unidades comparáveis de categorização para análise temática e de modalidade de codificação para o registro dos dados. Na exploração do material ocorrem operações de codificação, enumeração, classificação e agregação, em função de regras previamente formuladas. E no tratamento dos resultados, inferência e interpretação as informações brutas são tratadas de maneira a ser significativas. Com esses dados significativos, o investigador poderá propor inferências e interpretações a propósito dos objetivos previstos.

A presente pesquisa foi aprovada pelo Comitê de Ética em Pesquisa do Centro Universitário Franciscano, sob o parecer de no 775.964. Para garantir o anonimato, os nomes dos entrevistados foram substituídos pela letra "E" (entrevistado), seguido do número referente à ordem da entrevista.

\section{Resultados e Discussão}

Foram entrevistados dez alunos da instituição em questão, com idade entre 18 e 38 anos, de ambos os sexos e de cursos variados, tais como: psicologia, fisioterapia, filosofia, pedagogia, serviço social, enfermagem e nutrição. A partir da análise das entrevistas, surgiram duas categorias: aspectos socioculturais da alimentação e reflexos da globalização no comportamento alimentar. 


\section{Aspectos Socioculturais da Alimentação}

Esta categoria aborda a relação existente entre os aspectos sociais e culturais e o ato alimentar. Na maioria dos depoimentos, ficaram nítidas a importância e a vinculação direta que as relações sociais têm com o momento da refeição. Segundo Carneiro, ${ }^{7}$ o ato de comer, na maioria das vezes, não é um ato que se realiza sozinho, sendo esta a origem da socialização, pois até mesmo a linguagem pode ter sido desenvolvida pelo ser humano com o intuito de obter o alimento, além da criação de outras ferramentas culturais com o mesmo objetivo. O conceito de socialização é compreendido por Bauman ${ }^{14}$ como a interação do individuo com a estrutura social. Dessa forma, a prática de se alimentar teria como um de seus objetivos inserir o indivíduo na sociedade.

$\mathrm{O}$ ato do individuo em realizar as refeições ultrapassa as questões fisiológicas do organismo e exerce um papel muito mais amplo, conforme os relatos a seguir:

[...] é o alimento que faz a gente ter vínculos maiores, porque sempre, pode ver, se a turma quer fazer alguma coisa, tem que ter alguma coisa pra comer junto. Tudo que envolve pessoas envolve comida. É que a comida tem um forte vínculo afetivo [...]. (E1)

[...] na minha vida é um momento da gente conviver [...] e sempre que tu chama alguém é pra alguma coisa ligada ao alimento, nunca chama alguém só pra conversa. (E3)

[...] porque principalmente na família o momento da mesa, da refeição é o momento da conversa, chega a ser um laço afetivo a hora da refeição. (E7)

Acho que é uma questão de vínculos, e o momento também além da refeição é uma forma de se criar vínculos, conversa [...] acho que é fundamental, eu do prioridade quando posso, sempre busco tá envolvido com as pessoas e o que nos uni é a comida. (E9)

Os entrevistados relacionaram a hora da refeição a um momento de conversa e interação entre as pessoas, reconhecendo o lado social exercido pelo alimento. Para Lévi-Strauss, ${ }^{15}$ o alimento não serve somente para comer, mas também para pensar e comunicar. Fica evidente nas falas a importância da alimentação realizada em conjunto, trazendo novamente à tona a sociabilidade exercida nesta prática. Para Carneiro, ${ }^{7}$ a comensalidade é vista como o ato de comer em conjunto, dividindo o alimento, ele afirma que é um procedimento tão antigo que até mesmo espécies animais o praticam. O que diferencia a comensalidade humana da dos outros animais é o fato de atribuirmos sentidos para este ato, os quais se modificam com o passar dos tempos. Flandrin \& Montanari ${ }^{16}$ acreditam que o comportamento alimentar do homem difere do do animal não apenas pela cultura e pelo fato de prepararmos os alimentos, mas também pela função social exercida durante as refeições. 
A sociabilidade envolvida durante a alimentação abrange também a partilha de alimentos e os vínculos afetivos formados ou reforçados a partir deste ato, como foi citado pelos entrevistados. Segundo Assunção, ${ }^{17}$ a comida está associada aos laços afetivos e sociais, pois traz lembranças e sentimentos que nos reportam a lembranças das pessoas com quem nos relacionamos.

A cultura é outro aspecto que está intimamente ligada ao alimento, cada lugar, região ou grupo familiar têm costumes, tradições e hábitos específicos, próprios da sua cultura. As falas a seguir retratam este aspecto:

[...] a gente se reuni e faz o tradicional churrasco, sempre no domingo ou feriado. (E6)

É mais a questão dos domingos o churrasco, o almoço em família que tem o churrasco ou um risoto e maionese, que é sagrado, que isso já seria cultural, já vêm de anos assim, não muda né, que o meu pai fazia assim, o meu irmão mais velho também faz com a família dele e eu acho que eu também vô faze, é uma forma de reunir a família. (E9)

[...] todo domingo tem churrasco, é sagrado, então eu acho que é uma forma também da família tá reunida e tal, porque é o único dia que a gente pára pra conversar. (E9)

Como pode ser visualizado nos relatos, a questão cultural influencia diretamente o tipo de alimentação, os entrevistados relataram fazer parte de sua culinária o tradicional churrasco, feito principalmente em ocasiões especiais, como nos finais de semana, sendo algo que une a família. Com isso, Carvalho, Luz \& Prado $^{8}$ trazem a ideia de que a culinária e as tradições também refletem a vida social, na maneira de se reunir, de repartir o alimento e os trabalhos, seguindo noções postas pela sociedade e pela cultura. O ato de comer juntos é uma maneira de manter as relações. Assim como satisfazer a necessidade fisiologica, também é fator primordial na evolução da identidade cultural de uma sociedade. ${ }^{16}$

Dessa forma, a alimentação não é uma resposta apenas ao "comer para viver", é sim um ato humano culturalmente marcado, um fenômeno social. Lévi-Strauss, ${ }^{15}$ ao estudar a alimentação, já observava uma estreita relação entre natureza e cultura, elementos estes mediados pela cozinha, onde o alimento cru, (natural) ao passar pelo fogo, torna-se cozido, ou seja, cultural. Para Freitas, Minayo \& Fontes, ${ }^{18}$ "nada é mais natural que comer e nada é mais cultural que as formas, as preferências e os sentidos da alimentação".

Conforme constatado nas entrevistas, o caráter ritualistico ainda existe, os entrevistados realizam suas refeições na mesa e também utilizam este tempo para conversar:

Em casa é sempre na companhia da família, a gente tem o hábito de sentar à mesa ainda, todo mundo faz a refeição junto [...] na minha casa continua a mesma coisa, mas eu vejo que mudou bastante, porque os meus irmãos eles já são casados ai pra eles já é outro rítimo [...] então quando tá a família toda, até quando tá eu, o pai e a mãe, a gente ainda senta e conversa, na minha casa ainda continua assim, mas da pra ver que nos outros locais isso se perdeu. (E4) 
Ahh de todo mundo senta pra come junto sim, mas depende do dia. E de ficar na mesa conversando depois de comer, mas não é sempre, é quando da tempo. (E5)

A gente meio que segue o mesmo padrão todo dia, todo mundo senta junto no mesmo lugar, a TV tá ligada e a gente conversa assim sobre o que aconteceu no dia ou outro assunto, bem assim, quase sempre a mesma coisa. (E8)

Apesar de os entrevistados ainda realizarem determinadas refeições à mesa, esses momentos são influenciados por suas rotinas, o tempo disponível para fazer as refeições é conforme o dia da semana, alguns dias com mais atividades que outros. Nieble ${ }^{19}$ considera que o conceito de comensalidade envolve, entre outras coisas, a partilha de alimentos entre duas ou mais pessoas, representando também a convivência. Afirma ainda que as formas de produção social e suas consequências na estrutura social e familiar têm uma relação direta com os significados que o alimento adquire com o passar dos tempos, determinando modificações constantes nas maneiras de socialização doméstica.

Como pode ser observado nos relatos acima, os entrevistados ainda tentam preservar a rotina de sentar-se à mesa, disponibilizando o tempo necessário para este momento, o que, de acordo com Brasil, ${ }^{20}$ é o correto, pois é importante para a saúde e o bem-estar do organismo realizar refeições regulares, sem pressa e com atenção ao que se está comendo, considerando que o ato de comer também é fonte de satisfação e prazer.

Outras falas também reforçam tal aspecto:

Na companhia, com alguém, ah porque eu acho que é um momento de conviver, eu gosto de conviver nas refeições assim. (E3)

Com alguém, porque nossa é muito ruim fica quieta duas horas seguido e tu não ter com quem falar, aí às vezes eu pego o telefone e ligo pra mãe pra conversar com ela [...]. (E5)

Eu realizo as refeições com alguém e prefiro com alguém, ah porque tu vai comendo e vai conversando [...]. (E7) Na companhia, na maioria com alguém da minha família, eu não gosto de comer sozinh a [...] é muito difícil eu comer sozinha, sempre tem alguém junto [...] pra ficar conversando, não me sentir sozinha, ter uma distração. (E8)

Nos relatos acima é possível perceber que os entrevistados preferem realizar as refeições na companhia de alguém, ter com quem conversar e dividir o momento durante a refeição, tornando aquela ocasião mais agradável. Para Carneiro, ${ }^{1}$ a palavra "comensalidade" deriva do latim mensa, que quer dizer conviver à mesa, envolvendo não apenas o que se come, mas também como se come. Dessa forma, a comensalidade deixou de ser considerada apenas algo fisiológico ou biológico, é também um fator importante para a formação das estruturas de organização social, sendo manifestada a 
sociabilidade no momento da refeição partilhada. Segundo Visser, ${ }^{2}$ o comer acompanhado põe o individuo frente a um grupo, fazendo do ato de comer um meio para o relacionamento social. A palavra "companhia" deriva do latim companion, que quer dizer uma pessoa com quem partilhamos o pão, ato este que significa a própria amizade pela partilha. Estudo realizado por Alves \& Boog $^{21}$ sobre o comportamento alimentar em uma moradia estudantil revelou que para $20 \%$ dos entrevistados a presença de alguém não altera a refeição; para 37\%, às vezes sim, às vezes não; e para $43 \%$, alimentar-se acompanhado altera positivamente a refeição.

Todos os entrevistados relataram ter preferência por dividir o momento da refeição com alguém, pelo fato de ter uma companhia para conversar. Segundo Rodrigues, ${ }^{22}$ "o ato de comer não é um ato individual e sim uma atividade social. A comida deve ser partilhada e não consumida individualmente" (p. 87). Para Ackerman, ${ }^{23}$ os outros sentidos humanos podem ser apreciados em toda sua essência quando estamos sozinhos, mas o paladar é extraordinariamente social, de forma que os seres humanos dificilmente escolhem comer sozinhos.

A alimentação refere-se evidentemenre à ingestão de nutrientes, mas do mesmo modo importantes para a saúde, bem-estar e nutrição das pessoas, estão a alimentação adequada para o correto fornecimento de nutrientes e a importância social e cultural contida no ato de comer, promovendo a saúde e estimulando o convívio social. ${ }^{20}$ Se analisado do ponto de vista nutricional, o ideal é que as refeições sejam realizadas com alguém. Segundo o último Guia Alimentar para População Brasileira, as refeições realizadas em companhia evitam que as pessoas comam com rapidez e favorece a alimentação em ambientes mais adequados, pois refeições partilhadas necessitam de mesas e utensílios. Propõe ainda três recomendações que envolvem o ato de comer: comer em companhia, com regularidade e em ambientes apropriados. O Guia ressalta também que, seguindo tais recomendações, as pessoas terão um melhor aproveitamento dos alimentos no processo de digestão, melhor dominio sobre a quantidade que se está ingerindo e mais momentos para conviver com outras pessoas.

Outro aspecto que o alimento proporciona é a formação de vínculos entre as pessoas e, consequentemente, as lembranças geradas:

[...] quando eu vô tomar um café com leite com torrada, eu sempre me lembro de um fato da minha infância, lá em Porto Alegre quando a minha vó fazia torrada com café com leite sabe, então eu sempre recordo, e o ambiente que eu me lembro, era eu, a minha irmã e a minha avó [...]. (E2)

[...] o mingau de maisena da escola, me lembra aquela fase de criança. (E3)

[...] polenta, que me remete a minha infância, porque tinha a tia do meu pai que ela fazia polenta, a gente ia na casa dela e comia polenta com leite, polenta com açúcar, e quando eu como polenta com açúcar eu lembro da minha infância, é um alimento que me lembra bem assim. (E4)

Comida de vó, principalmente carne de panela, cozida com molho que a vó faz muito bem, me lembra a infância, que eu passei muito tempo com ela, eu sinto o cheiro de cebola refogada, do alho, da carne e eu lembro de vó. (E7) 
Os alimentos rememorados pelos entrevistados são carregados de afetividade e recordações, foram mencionadas comidas que lembram alguém ou algum momento marcante. Rodrigues ${ }^{22}$ propõe que a alimentação envolve vários aspectos dentre os quais as emoções e as lembranças. Para o autor, um prato, sua aparência, seu aroma e as pessoas envolvidas são todos elementos favoráveis para tornar especial tal momento e a experiência de convívio nele vivenciado.

\section{Reflexos da Globalização no Comportamento Alimentar}

Nesta categoria, buscou-se investigar questões que acabam interferindo diretamente na qualidade e no momento da alimentação. Foi observado o consumo de alimentos industrializados e semiprontos, que, devido a sua praticidade, acabam sendo bastante utilizados em função do tempo, gerando uma transição de padrões alimentares e influenciando o modo de socialização do alimento. Nas últimas décadas, aconteceram e estão acontecendo grandes mudanças globais nos padrões alimentares, que geram importantes consequências sociais. Um dos fatores decisivos na influência desses padrões alimentares é, sem dúvida, a indústria. O declínio das refeições realizadas em família resulta na corrosão do próprio conceito de "refeição", numa sociedade em que, cada vez mais, seja no trabalho ou em momentos de diversão, a preferência pela "alimentação rápida" se tornou rotineira. Tais transformações têm sido enfocadas com certa frequência, justamente por se tratar de um processo que está acontecendo nas sociedades atuais. ${ }^{1}$

A influência do tempo no comportamento alimentar foi evidenciado nas falas a seguir:

É bem complicado assim, eu não consigo fazer aquelas alimentações de três em três horas, eu acho que a própria atualidade assim não permite, porque como eu levo a universidade com o trabalho, e filho, e marido, tudo junto, dai eu tenho bastante restrição assim de ter que ter tempo e tudo mais [...]. (E3)

Ahh o tempo influencia, eu não tomo café, almoço e janto, e às vezes não dá tempo de faze um lanche de tarde nem de manhã [...] sim, gostaria que tivesse mais tempo [...]. (E4)

Falta o tempo pra preparar, o ideal é preparar e não comer os lanches daqui. (E7)

[...] ah que eu tivesse mais tempo, de manhã principalmente pra tomar um café, que as vezes eu fico morrendo de fome na aula, de tardezinha também, que eu tenho aula as sete, as vezes não dá tempo de fazer o que eu queria por questão de tempo, também gostaria de poder escolher, tipo de cozinhar em casa, comer coisas diferentes, não ficar só na comida pronta [...]. (E8)

Eu não consigo realiza as refeições tranquilamente, porque eu acho que é muito corrida a rotina da universidade [...] eu gostaria de sentar e almoçar tranquilamente, uma comida quentinha, pronta, feita na hora, porque de segunda a sexta eu não almoço como deveria almoçar, que é aquela alimentação adequada. (E9) 
Nota-se que o tempo influencia a rotina alimentar dos entrevistados. Pela falta de tempo muitos não fazem algumas refeições durante o dia e os que conseguem nem sempre é da maneira como desejariam. Outra questão vista é que os entrevistados gostariam que suas rotinas fossem diferentes, a principal mudança seria possuir mais tempo para preparar e realizar as refeições adequadamente. Sabe-se que o tempo influencia e contribui para mudanças no convívio dos indivíduos no momento de se alimentar. Bauman, ${ }^{24} \mathrm{em}$ seu conceito de modernidade líquida, traz a ocorrência de mudanças nas maneiras de socialização entre os indivíduos, devido à rapidez do tempo:

A nova instantaneidade do tempo muda radicalmente a modalidade do convívio humano - e mais conspicuamente o modo como os humanos cuidam (ou não cuidam, se for o caso) de seus afazeres coletivos, ou antes o modo como transformam (ou não transformam, se for o caso) certas questões em questões coletivas (p. 147). ${ }^{24}$

Um ponto bastante favorável observado nesses relatos é que os entrevistados, apesar de não conseguirem, na maioria das vezes, ter tempo para preparar os alimentos ou para uma rotina de alimentação adequada, ainda parecem se importar e ter consciência de alguns aspectos relacionados à esta questão. Segundo Brasil, ${ }^{20} \mathrm{o}$ acesso a informações sobre alimentação saudável é fundamental para que as pessoas possam optar por nutrientes mais adequados, porém aderir a um estilo de vida mais salutar não é apenas uma questão de opção, muitos fatores podem influenciar, entre eles o tempo.

Devido à falta de tempo para preparar as refeições, atualmente muitas pessoas estão optando por uma alimentação mais rápida e isto tem refletido nas mudanças sociais relacionadas ao comportamento alimentar, como mostram as falas a seguir:

[...] no jantar quando tem menos gente em casa, a gente come uma pizza, uma coisa mais rápida... um miojo, um hamburger, que é mais pratico né, mais rápido. (E4)

[...] eu acho que eu comeria melhor e coisas mais saudáveis se fosse em casa e não na rua, porque tu acaba querendo come muito, tu enxerga aquela bobagem e tá com muita fome e "ahé só hoje" o o só hoje vai todo dia. (E5)

[...] quando não tem [comida] pronta ou não tem tempo de fazer o almoço, quando eu chego muito cansada durante a semana, ai a gente come alguma coisa congelada né, coloca no microondas e vai mais rápido, [...] mais pela falta de tempo [...]. (E7)

As vezes eu chego dez e meia onze horas em casa e tem que acordar cedo no outro dia, então fazer comida seria muito difícil, é mais fácil pegar um xis. (E8)

Consumo bastante, acho que em função do tempo, não tanto por não ter tempo, mas por praticidade, por ter outras coisas pra fazer, porque eu até gosto de cozinhar, mas por praticidade pra não perder tempo, e eu gosto bastante, tu coloca no microondas e fica pronto, e tem muitas coisas que são bem boas, o hamburger, a minipizza. (E8) 
Como observado nas falas, pela falta de tempo, os entrevistados acabam consumindo, com bastante frequência, comidas semiprontas, fast foods, industrializados ou de restaurantes, por causa da rapidez e praticidade com que esses alimentos ficam prontos. Tais transformações na forma de se alimentar refletem na sociabilidade da alimentação e na saúde das pessoas. Dessa forma, Nieble $^{19}$ acredita que a alimentação sofre transformações constantes, tanto no que diz respeito a sua preparação quanto ao modo como as pessoas se alimentam. Porém, isso não significa que a alimentação perdeu seu caráter ritualístico, mesmo com a influência norte-americana do fast food. No entanto, com a descoberta de que algumas doenças podem estar relacionadas com certos tipos de comida, as pessoas estão modificando alguns hábitos e significados alimentares. Os rituais de alimentação passaram por um esvaziamento, principalmente após o surgimento dos fast foods, a rapidez proporcionada por este tipo de alimentação facilitou o deslocamento das refeições para outros locais, como uma mesa de trabalho ou para frente da televisão. Este movimento pode ter levado ou estar levando à diminuição da consciência do ato de se alimentar. ${ }^{10}$

Carneiro $^{7}$ afirma que a alimentação fast-food tem sido relacionada com grande parte dos problemas sociais atuais. Observa-se uma ruptura dos padrões alimentares nas famílias, as refeições que antes eram partilhadas, hoje acontecem com menos frequência, por exemplo. Está havendo uma substituição da alimentação realizada em casa por restaurantes ou lanchonetes. E o grande problema é que algumas cadeias de lanchonetes têm como característica um sistema alimentar baseado na substituição dos carboidratos complexos por carboidratos simples, com consequências danosas para a saúde de quem consome.

Portanto, ainda que tenham ocorrido mudanças na forma atual de se alimentar, nota-se que o hábito de fazer a refeição em grupo e a satisfação envolvida não deixou de estar presente. Mesmo quando a refeição é realizada fora de casa, em restaurantes ou locais que servem comida "rápida", ainda há o contentamento por partilhar o momento com outra pessoa, pois para muitos o fato de se alimentar sozinho faz com que a comida não tenha o mesmo sabor. ${ }^{19}$

Segundo várias falas, o uso do microondas é bastante referido como forma de praticidade, porém Carneiro $^{1}$ acredita que o uso desse eletrodoméstico pode facilitar o ato de as pessoas comerem sozinhas, contribuindo para o fim das refeições em grupo. Estas preferências por facilidades que diminuem o tempo de preparo dos alimentos é uma caracteristica do comensal urbano atual. ${ }^{25}$

Outro aspecto observado foi a relação entre alimentação e outras funções desempenhadas ao longo do dia, como mostram os relatos abaixo:

Como eu tenho várias atividades, por exemplo, é o PIN que élá na Secretaria de Saúde, é aqui, então lá mesmo não tem algo perto pra sair e comprar alguma coisa, então lá interfere, ai eu tenho que levar alguma coisa e às vezes não dá tempo de pegar e botar na bolsa ou ir até o mercado pra comprar, então interfere sim e bastante. (E2) 
O emprego não, mas a correria dele sim, hoje todo mundo né, a vida urbanizada não adianta, é a correria, a gente corre atrás do prejuizo, eu sei que teria como ter um planejamento melhor da minha parte, mas é mais fácil tu comprar do que fazer, parece. (E7)

Às vezes eu tenho reuniões, por exemplo, hoje que eu tenho uma reunião as cinco horas e depois já fico pra aula, volto pra casa só as onze, daí interfere muito porque eu vô te que comer alguma coisa por lá, ai acaba sendo um pastel, alguma coisa mais gordurosa, então interfere bastante pela questão de que eu tô longe de casa e não tem muita escolha. (E8)

Pela análise feita nos depoimentos, pode-se notar que as atividades que os entrevistados desempenham ao longo do dia interferem em suas rotinas alimentares, refletindo na diminuição do tempo disponível para preparar alimentos ou mesmo buscar opções mais saudáveis.

A comensalidade contemporânea caracteriza-se pela falta de tempo no momento do preparo e consumo dos alimentos, pela adoção de produtos industrializados, pelo deslocamento das refeições e pelo aumento da individualização dos rituais alimentares. Outra questão analisada pela autora é que a alimentação contemporânea passou a ser motivo de preocupação na área da saúde, desde que estudos epidemiológicos mostraram a ligação entre o consumo de comida industrializada e algumas doenças crônicas associadas a este tipo de alimentação. ${ }^{25}$

O excesso de alimentos industrializados incorporados na alimentação diária pode ter sérias consequências na saúde de quem os consome. Segundo Tardido \& Falcão, ${ }^{26}$ a industrialização trouxe um aumento no consumo de calorias, resultando em maior ingestão calórica e menor gasto energético, com consequente acúmulo de gordura. Outra característica citada pelos autores que reforça a adoção de hábitos alimentares não tão saudáveis é a substituição do arroz, feijão e salada por refrigerantes, salgadinhos e biscoitos.

Enfim, a globalização, a indústria e os serviços de alimentos fornecem à vida contemporânea a otimização do tempo e do trabalho, pois no curto tempo que as pessoas possuem para comer, a pressa é a principal característica vista nos centros urbanos, tendo como consequência um encurtamento do ritual alimentar, tanto na fase de preparo como de consumo, tornando o comer somente uma operação de reabastecimento. ${ }^{25}$.

\section{Conclusão}

Com base no estudo, foi possível notar a influência social, cultural e os sentidos e significados que a alimentação possui na rotina diária dos entrevistados, a importância que exerce no convivio social, fato que sempre esteve presente, fazendo parte do desenvolvimento do homem. O comportamento alimentar de diferentes grupos sociais vem se alterando com o passar do tempo, porém, apesar 
das mudanças, nota-se que o ato social envolvido na alimentação é o que permanece até os dias de hoje, ainda que modificado. Esta série de alterações aconteceram devido a diversos fatores, entre eles, principalmente, o tempo.

Entre as limitações do estudo, destaca-se o pouco tempo disponível dos entrevistados, o que impediu que grande parte das pessoas abordadas não pudessem dele participar. Tal fato vem ao encontro dos resultados obtidos neste trabalho, em que se evidenciou que a falta de tempo é característica do atual comensal, que possui muitas atividades ao longo do dia e necessita conciliar todas elas. Por fim, sugere-se novas pesquisas com este tema, visto ser um campo bastante amplo e que possibilita um outro olhar à alimentação, que nem sempre é explorado pela nutrição. Os estudos no campo da alimentação e nutrição não comportam abordagens e olhares unilaterais, é necessário cada vez mais incorporar o saber das Ciências Sociais neste diálogo. O novo Guia Alimentar para a População Brasileira, lançado recentemente, representa um grande avanço nessa direção, de um movimento na ciência da nutrição que busca compreender os aspectos sociais e culturais contidos no ato de comer.

\section{Referências}

1. Carneiro H. Comida e sociedade: uma história da alimentação. Rio de Janeiro: Campus; 2003. 204 p.

2. Visser M. O ritual do jantar: as origens, evolução, excentricidades e significado das boas maneiras à mesa. Rio de Janeiro: Campus; 1998. 430 p.

3. DaMatta R. O que faz o brasil, Brasil? Rio de Janeiro: Rocco; 1986.

4. Maciel ME. Identidade cultural e alimentação. In: Canesqui AM, Garcia RWD. Antropologia e nutrição: um diálogo possível. Rio de Janeiro: Editora Fiocruz; 2005.

5. Bosi MLM, Prado SD. Alimentação e nutrição em saúde coletiva: constituição, contornos e estatuto científico. Ciênc. Saúde Coletiva 2011; 16(1):7-17.

6. Santos CRA. A alimentação e seu lugar na história: os tempos da memória gustativa. História: Questões e Debates 2005; (42):11-31.

7. Carneiro H. Comida e sociedade: significados sociais na história da alimentação. História: Questões e Debates 2005; (42):71-80.

8. Carvalho MC, Luz MT, Prado SD. Comer, alimentar e nutrir: categorias analíticas instrumentais no campo da pesquisa científica. Ciênc. Saúde Coletiva 2011; 16(1):155-163.

9. Giddens A. As consequências da modernidade. São Paulo: Editora UNESP; 1991. 117 p.

10. Garcia RW. Práticas e comportamento alimentar no meio urbano: um estudo no centro da cidade de São Paulo. Cad. Saúde Pública 1997; 13(3):455-467. 
11. Lefevre F, Lefevre AMC. Os novos instrumentos no contexto da pesquisa qualitativa. In: Lefevre F, Lefevre AMC, Teixeira JJV. O discurso do sujeito coletivo: uma nova abordagem metodológica em pesquisa qualitativa. Caxias do Sul: EDUCS; 2000.

12. Mayan MJ. An introduction to qualitative methods: a training module for students and professionals. Edmonton: Universidade of Alberta; 2001. 70 p.

13. Bardin L. Análise de conteúdo. Lisboa: Edições 70; 1977. 225 p.

14. Bauman Z. Ética pós-moderna. São Paulo: Paulus; 1997. 288 p.

15. Lévi-Strauss C. O cru e o cozido. São Paulo: CosacNaify; 2004. 442 p. Mitológicas, 1.

16. Flandrin JL, Montanari M. História da alimentação. São Paulo: Estação Liberdade; 1998. 885 p.

17. Assunção VK. Comida de mãe: notas sobre alimentação, família e gênero. Caderno Espaço Feminino, 2008; 19(1):233-253.

18. Freitas MCS, Minayo MCS, Fontes GAV. Sobre o campo da alimentação e nutrição na perspectiva das teorias compreensivas. Ciênc. Saúde Coletiva 2011; 16(1):31-38.

19. Nieble BD. Comensalidade através dos tempos. Contribuciones a las Ciencias Sociales. Mar 2010. Disponível em: http//www.eumed.net/rev/cccss/07/bdn.htm

20. Brasil. Ministério da Saúde. Secretaria de Atenção à Saúde. Departamento de Atenção Básica. Coordenação Geral da Política de Alimentação e Nutrição. Guia alimentar para população brasileira. Brasília: Ministério da Saúde; 2014.

21. Alves HJ, Boog MCF. Comportamento alimentar em moradia estudantil: um espaço para promoção da saúde. Rev. Saúde Pública 2007; 41(2):197-204.

22. Rodrigues H. Alimentação como fonte de sociabilidade e de hospitalidade. Revista Sinais 2012; 1(12):85-100.

23. Ackerman D. Uma história natural dos sentidos. Tradução Ana Zelma Campos. 2. ed. Rio de Janeiro: Bertrand Brasil; 1996. 368p.

24. Bauman Z. Modernidade líquida. Rio de Janeiro: Jorge Zahar; 2001. 258p.

25. Garcia RW. Reflexos da globalização na cultura alimentar: considerações sobre as mudanças na alimentação urbana. Rev. Nutr. 2003; 4(16):483-492.

26. Tardido AP, Falcão MC. O impacto da modernização na transição nutricional e obesidade. Revista Brasileira de Nutrição Clínica 2006; 21(2):117-124.

Recebido: 23/3/2015

Aceito: $21 / 10 / 2015$ 